\title{
The Commission on Chronic Illness
}

\author{
By DEAN W. ROBERTS, M.D., M.P.H.
}

$\mathrm{T}$ HE COMMISSION on Chronic Illness is past the halfway mark in its 7-year life. It is well along in the work it set out to do, although as envisaged by its founders, the effects of this work will extend far beyond the duration of the organization.

The commission is a creation of the American Hospital Association, the American Medical Association, the American Public Health Association, and the American Public Welfare Association, which in 1945 took a concerted step in the attack on chronic disease by forming the Joint Committee on Chronic Illness.

Each of the organizations had been increasingly aware of the magnitude and importance of the problem of chronic illness. Each was intimately concerned with one or more aspects of the problem, and it was apparent that no one of them could move very far toward its solution without encountering the need for help and advice from the others.

The joint committee continued for 2 years, and its work reached its peak in the production of the joint statement, Planning for the Chron-

Dr. Roberts has been director of the Commission on Chronic Illness since July 1, 1952. He was one of the representatives of the American Public Health Association on the Joint Committee on Chronic Illness and a charter member of the Commission on Chronic Illness. From 1945 to 1950 he was chief of the bureau of medical services of the Maryland State Department of Health, where he developed Maryland's medical care program for the indigent and the chronic disease hospital program. ically Ill (1). By 1947 it was clear that an independent organization under proper auspices would be a powerful instrument for review and assessment of the chronic disease problem. Its members would have unlimited scope for their efforts, unhampered by the inevitable conditioning factors involved in an official relationship with a permanent professional association. At the same time they would have ready access to the resources of knowledge and information which the sponsoring organizations possess.

In May 1948, the National Health Assembly met in Washington for a 4-day session. One of the sections devoted its attention to chronic disease and aging under the chairmanship of Dr. James R. Miller. One of the important recommendations of this section was that "the existing Joint Committee on Chronic Disease of the American Hospital Association, American Medical Association, American Public Health Association and American Public Welfare Association should be continued and constituted as a national commission and its membership should be expanded to include appropriate representatives from other disciplines, organizations, and interests in the field of chronic illness ...." and that "the work of the commission should be encouraged by the provision of funds from private sources and by support from the Government in the form of both funds and personnel."

Under the leadership of Dr. James R. Miller, a trustee of the American Medical Association, the joint committee constituted itself as the Interim Commission on Chronic Illness in November 1948, and for the next six months developed specific plans for the objectives, organiza- 
tion, membership, and financial support for the commission.

Its proposals culminated in the establishment in May 1949 of the Commission on Chronic Illness as an independent, nonprofit organization, with Leonard W. Mayo, director, Association for the Aid of Crippled Children, New York, as its chairman.

\section{Membership and Goals}

The commission has 34 members representing the medical and other health professions, industry, labor, agriculture, education, welfare, religion, journalism, the social sciences, and the general public. Each member serves as an individual rather than as a representative of an organization. Advice and consultation from any of a panel of 37 technical advisers is available at all times.

Each of the founding organizations has designated a staff associate to the commission. Staff associates have also been assigned by the American Nurses Association, the National League for Nursing, and the American Dental Association. The staff associates serve as liaison between the commission and the organized fields of activity they represent.

Briefly stated, the commission's founders have regarded it as an instrument to bring order, cohesion, and direction to the many related but unintegrated efforts to prevent and control chronic illness and to minimize its disabling effects. Since its founding the commission's philosophy and actions have been subscribed to in the form of financial and other support by two additional national professional associations, seven national voluntary organizations in the health field in addition to the National Health Council, the Public Health Service, three leading foundations, four of the large life insurance companies, and a university.

At its first meeting the commission decided on three main objectives: to gather and transmit information on current activities and plans designed to cope with the many-sided problem of chronic illness; to make or have made new studies needed to provide a sound basis for planning in this field; and to formulate suggested programs of action by national, State, and local agencies and groups. It set six goals :
1. Define the problems arising from chronic illness in all age groups.

2. Pave the way for dynamic programs to prevent chronic illness, minimize its disabling effects, and restore victims to a socially productive place in the community.

3. Clarify the interrelationships of the many professional groups and agencies working in the field.

4. Coordinate the separate programs for specific diseases with a general program designed to meet more effectively the needs common to all the chronically ill.

5. Stimulate in every locality a well-rounded plan for the prevention and control of chronic disease and for the care and rehabilitation of the chronically ill.

6. Modify society's attitude that chronic illness is hopeless.

The commission early decided that it would be able to conduct only a limited amount of research and that to reach its goals it would rely primarily on aiding and stimulating research by others, and on national conferences called under its auspices.

\section{National Conferences}

The first of these conferences, cosponsored by the National Health Council and the Public Health Service, was devoted to the preventive aspects of chronic disease. It was held in Chicago in the spring of 1951 (2).

The commission had already adopted and elaborated on the 1946 statement of the Joint Committee on Chronic Illness that "the basic approach to chronic disease must be preventive." Now it assembled current knowledge concerning prevention and called together a group of national authorities to explore the present situation and future possibilities.

The conference stressed the need for additional research, including research on screening tests and mass screening programs. It outlined general criteria for evaluation of screening. It asked that research be undertaken to establish the validity and reliability of specific screening tests and suggested studies to improve the planning and conduct of mass screening programs.

The conference concluded that there is an impressive amount of knowledge physicians can 
apply in preventing the occurrence of chronic disease, and it gave in detail ways in which the medical profession can use this knowledge to good effect in the community. It also recognized the need for education to the end that individuals will give physicians a chance to help them keep well, before they become ill.

The conference recommendations have found wide use in medical schools, schools of public health, and elsewhere in professional education, and to a lesser extent in community planning.

The conference on care of the long-term patient, to be held in Chicago March 18-20, 1954, will be the second of the commission's national conferences. The Public Health Service is joining with the commission's four founders in sponsoring this conference, and the list of participating organizations carries the names of 39 national groups concerned with one or more aspects of long-term care. Approximately 400 invited delegates, representative of all the disciplines concerned, will attend.

The meeting will focus on the health services needed by the more than 5 million persons who are substantially disabled by chronic illness or other impairment.

The conference will attempt to identify the requirements of the long-term patient in the various stages and degrees of his illness. It will examine existing methods of providing care, explore new methods, and enunciate principles which should guide suggested changes, and suggest patterns for desirable relationships between services, facilities, and programs. It is hoped that it can recommend various ways to improve the financing of long-term care, and that it can establish direction and set next steps for local, State, and national programs for the care of the long-term patient.

To this end study groups across the country have been working for many months, each on a fairly narrow segment of the various aspects of care. Their reports will form a basis for discussion.

At the conference, the members of these study groups, augmented by additional experts drawn from many disciplines, will work in five major committees. These committees and their chairmen are: the patient at home, Dr. Martin Cherkasky, director, Montefiore Hospital, New
York City; the patient in an institution, Dr. Anthony J. J. Rourke, executive director, Hospital Council of Greater New York; integration of facilities and services, Dr. Milton Terris, assistant dean for postgraduate education, School of Medicine, University of Buffalo; research, Dr. Thomas Parran, dean, Graduate School of Public Health, University of Pittsburgh ; and financing, Dr. Theodore G. Klumpp, president, Winthrop-Stearns, Inc., New York City. Mrs. Lucille M. Smith, Public Health Service, a member of the Commission on Chronic Illness, is executive secretary of the conference.

\section{Rural and Urban Studies}

The commission's national conferences are held against a background of other actions and developing activities designed, like the conference, to achieve the commission's stated goals.

Major current undertakings are two studies of chronic illness prevalence and needs for care, one in a rural community, Hunterdon County, N. J., and the other in an urban community, Baltimore, Md.

These are the first studies to measure the needs for various types of care for chronic illness, and they are designed to produce added dividends in terms of new knowledge relating to collection of morbidity data and to the validity and reliability of mass screening procedures.

The rural and urban studies roughly parallel each other and are being conducted through a series of planned steps. A beginning step is an interview with the selected families which constitute the sample. In Hunterdon County the interviews are conducted by specially trained local school teachers and in Baltimore, by Census Bureau staff. The initial interview identifies family members who are reported to have a chronic disease and provides details about the diseases and conditions reported. Permission to consult existing medical records is requested.

The next step is a diagnostic examination and evaluation of a representative sample of the persons reported as having a chronic disease and a sample of those reported to be well. A team composed of a physician, nurse, social worker, and vocational counselor makes this evaluation. This step is expected to establish 
or confirm the good health or illness reported in the original interviews and to supply estimates on the services and facilities needed by each patient and the rehabilitation potential of each patient, as well as rehabilitation services required. The team will attempt to determine what preventive medical services could have been helpful and to evaluate the socioeconomic problems which may have been obstacles to treatment and care of the patient.

As another phase of the study, an additional subsample of the population interviewed will be given a battery of screening tests including height, weight, vision, hearing, dental examination, blood sugar, hematocrit, serologic test for syphilis, urinalysis, and electrocardiogram. This step will also include a followup diagnostic examination of a sample of persons for whom the screening tests indicated positive results and similar followup examinations of persons with negative results. The procedure will provide a test of the validity and reliability of the multiple screening tests. It should indicate how much unrecognized disease that can be proved to exist is actually present in a given population; the maximum "yield" through early detection; how much of the unrecognized disease can be brought to light through multiple screening, and at what cost. The answers to these questions will provide a basis for deciding whether present knowledge of multiple screening tests as a method of early detection is great enough to warrant widespread use, and it will help to implement the recommendations of the conference on preventive aspects with respect to evaluation of screening procedures.

The Baltimore study will include, as a final step, rehabilitation services for persons identified as having a rehabilitation potential which might enable them to return to remunerative employment, including housework and homebound industry. Thus, it is expected that the reliability of the method of estimating rehabilitation potential can be evaluated.

Since one of the outstanding facts about chronic illness is the lack of up-to-date national figures, the commission is exploring the possibilities of using the Baltimore and Hunterdon County experience to project a system for collecting accurate national data expeditiously.
The Baltimore questionnaire developed by the Census Bureau is an excellent instrument for collecting illness data by interview. Both studies provide a test of the accuracy of the information so obtained, and from this test a plan for error correction could be evolved.

The Hunterdon study is being done in cooperation with the Hunterdon Medical Center, the New Jersey State Department of Health, and the National Opinion Research Center, with the aid of a grant from the Commonwealth Fund. In the Baltimore study, the Census Bureau, Johns Hopkins University and Hospital, and the Division of Vocational Rehabilitation of the Maryland State Department of Education are cooperating. The Commonwealth Fund is assisting in the financing in Baltimore. Both studies have been aided by Public Health Service grants, with the major share of the cost of the Baltimore project being paid from Federal funds.

\section{Nursing Home Patients}

A second major research project now under way is a study of characteristics of patients in nursing homes and related establishments, such as homes for the aged, almshouses, and chronic disease hospitals.

There is very little information about these persons. Even the number of patients in nursing homes and the number of such establishments is in doubt, although hazy estimates run upward of 9,000 nursing homes with 150,000 patients. What care these persons need and are receiving is virtually unknown.

The pilot study was done in Maryland with the cooperation of the Maryland State Department of Health, the Maryland Association of Registered Nursing Homes, and the Division of Hospital Facilities of the Public Health Service. It produced detailed information on who the patients are; how long they have been in the various institutions; who pays for their care; what ailments they suffer; the nature and extent of disability; and the kinds and amount of care they receive.

In followup of the Maryland pilot study, 10 other States are now participating in the commission survey, making parallel studies of their nursing homes and related institutions. The 
commission is supplying uniform questionnaires and procedures for conducting the survey and the services of a consultant who worked on the pilot study.

\section{Home Care Program Survey}

Still a third research project is the survey of home care programs, undertaken by the commission, the Division of Chronic Disease and Tuberculosis and the Division of Public Health Methods of the Public Health Service. It was prompted by the need for factual material with which to answer an increasing volume of inquiries about home care programs as a possible aid in caring for the chronically ill. Its purpose is "to obtain basic factual data on the organization, development, and operation of selected organized home care programs; to formulate broad principles for the organization, development, and operation of home care programs; to make this information available to program operators, consultants, and persons interested in planning new programs; and to describe the use of home care programs in professional education."

Field work began in Richmond, Va., in October 1952. At the invitation of the Richmond Health Department and the Medical College of Virginia, a study team composed of physician, nurse, social worker, and statistician from the Public Health Service gathered pertinent information about the Richmond plan. The study plan was then reviewed, in the light of the Richmond pilot study, to evaluate the schedule forms and the techniques used.

Subsequently, 10 other programs in 8 States were surveyed.

A report is being prepared and should be available in May. It will cover the objectives of the programs in the sample, the auspices under which they operate, the services they provide, administration and staff, eligibility for service under the programs, and source of program funds.

\section{Maintains Clearinghouse}

The commission has gathered facts on chronic disease activities of councils of social agencies and community chests, visiting nurse associations, hospitals, medical societies, and health departments. To stimulate community studies of existing resources and their better use, the commission, as one of its first acts, developed and published a model community survey which has been widely used and continues to be in demand.

An active clearinghouse of information on chronic illness programs and activities now under way throughout the country is maintained in the commission's Baltimore headquarters. 'Through the monthly Chronic Illness News Letter, new demonstrations, building programs, studies, and similar activities are brought to the attention of the 10,000 people who receive the publication-persons connected with the many aspects of chronic disease programs.

The complex of interrelated problems touching on chronic illness is so vast that to some it may appear overwhelming. However, it is the experience of the commission that substantial progress can be made by identifying the individual components of the problem and submitting these components to intensive study and research. There are literally hundreds of highly trained persons from many disciplines who singly and in small groups are working with the commission, concentrating on some particular facet of the chronic illness problem. It is clear that when the commission closes its books in 1956, chronic illness will still be with us, but it is not unreasonable to hope and to expect that the nature of the problem will have been considerably clarified and constructive plans for action developed. In any event, that is the end toward which the commission works. Meanwhile, it is encouraging to find that so many communities are alert to the problem, are ready to take action, as soon as they know what action to take.

\section{REFERENCES}

(1) Planning for the chronically ill. Joint statement by the American Hospital Association, American Medical Association, American Public Health Association, and American Public Welfare Association. Hospitals 21: 108, 110, 112 (Nov. 1947) ; J. A. M. A. 135 : 343-347 (1947) ; Am. J. Pub. Health 37 : 1256-1266 (1947) ; Public Welfare 5 : 218-224 (1947).

(2) Conference [on] Preventive Aspects of Chronic Disease, Chicago, March 12-14, 1951. Raleigh, N. C., Health Publications Institute, 1952. 311 pp. 